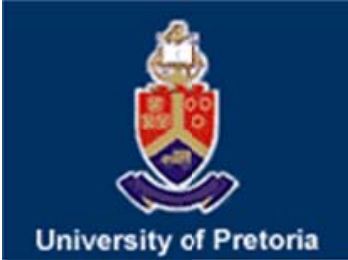

University of Pretoria

Department of Economics Working Paper Series

Investor Sentiment Connectedness: Evidence from Linear and Nonlinear Causality Approaches

Aviral Kumar Tiwari

Montpellier Business School

Deven Bathia

Queen Mary University of London

Elie Bouri

Holy Spirit University of Kaslik

Rangan Gupta

University of Pretoria

Working Paper: 2018-14

February 2018

Department of Economics

University of Pretoria

0002, Pretoria

South Africa

Tel: +27 124202413 


\title{
Investor Sentiment Connectedness: Evidence from Linear and Nonlinear Causality Approaches
}

\author{
Aviral Kumar Tiwari`, Deven Bathia*, Elie Bouri and Rangan Gupta`
}

\begin{abstract}
This paper provides a novel perspective in determining the causality of sentiment across US, Latin America, Eurozone, Japan and Asia (excluding Japan), based on monthly data covering the period of January 2003 to November 2017. Using a survey-based sentiment index of 'sentix', our results tend to suggest strong evidence of nonlinearity and structural breaks making the results from linear causality models unreliable. Using a kernel-based multivariate nonlinear causality test, we find that causality runs from Eurozone to US, Asia, and Japan, with Japan also causing the Eurozone sentiment, and Latin-America causing Japanese sentiment. Interestingly, when we applied rolling estimations to detect time-varying causality for the cases of Eurozone and US, Eurozone and Asia, Eurozone and Japan, and Latin-America and Japan, we found evidence of bi-directional spillovers during certain months of the recent global financial crisis, and thereafter. Overall, our findings indicate that the sentiments of Japan, Asia, and US are related quite strongly with that of the Eurozone, as is Japan and Latin America.
\end{abstract}

Keywords: Sentiment Spillovers; Linear and Nonlinear Causality; US; Latin America; Eurozone; Asia.

JEL Codes: C32, G40.

\footnotetext{
- Montpellier Business School, 2300, avenue des Moulins, 34185 Montpellier cedex 4 0002, France. Email: aviral.eco@gmail.com.

* Queen Mary University of London, School of Business and Management, Mile End Road, London, E1 4NS, United Kingdom. Email: d.bathia@qmul.ac.uk.

- Corresponding author. USEK Business School, Holy Spirit University of Kaslik, Lebanon. Email: eliebouri@,usek.edu.lb.

`Department of Economics, University of Pretoria, Pretoria, 0002, South Africa. Email: rangan.gupta@up.ac.za.
} 


\section{Introduction}

\section{"Bull markets are born on pessimism, grow on scepticism, mature on optimism and die on euphoria" (Sir John Templeton)}

The above quote simply embeds the state of affairs of the global financial markets due to investors' behaviour. Such a view held by a legendary investor about financial markets show that investors don't ignore their prevailing sentiment levels in financial markets when making investment decisions. Words like 'pessimism', 'scepticism', 'optimism', and 'euphoria' reflect the sentiment of investors at varying levels, and have become the standard lexicon in the popular press in recent years to explain the performance of financial markets. Precisely, 'Investor sentiment' represents investor's optimism and pessimism about the future returns. According to Brown and Cliff (2004), it represents the expectations of market participants relative to a norm: a bullish (bearish) investor expects returns to be above (below) average, whatever average maybe.

Numerous studies have investigated the effects of investor sentiment on stock returns. As such, they have studied the significance of both survey-based (direct) and market-based (indirect) sentiment measures on financial markets. For instance, Lemmon and Potniaguina (2006) find that consumer confidence index is useful in forecasting small-cap stock returns as well as returns of stocks with low institutional ownership. Brown and Cliff (2005) argue that the role of uninformed demand shocks and limits to arbitrage can explain securities mispricing. Similar views are shown by Baker and Wurgler (2006) who indicate that small, young, highly volatile, unprofitable, non-dividend paying, extreme growth and distressed stocks are usually a victim of investor sentiment, and have subjective valuations. Few studies have looked at the propagation of sentiment across international financial markets (Verma and Soydemir, 2006; Bathia et al. 2016). However, the extent to which investor sentiment is affected by the prevailing sentiment levels across country/ region has not been investigated for any countries/ regions. Given that the sentiments of investors are the reflection of individual's behaviour, one can wonder who these sentiments spill over across major countries /regions. In this paper, we address this research question. Specifically, we use an entropy causality approach. As a proxy for investor sentiment, we use sentix, 'survey-based' sentiment indices to determine the causality across five countries and regions, namely, United States, Latin America, Eurozone, Japan, Asia excluding Japan for the period January 2003 to November 2017. Since our study includes both developed (the United States, Eurozone and Japan) and developing markets (Latin America, Asia excluding Japan), it will be the first study to investigate the causality of 
sentiment across these markets. Prior studies have mainly looked at either time-series or crosssectional relationship between investor sentiment and asset returns. Furthermore, these studies were mostly centred around developed markets (Baker and Wurgler, 2006; Schmeling, 2009; Bathia and Bredin, 2013). Our study on the causality of sentiment across developed and developing regions will provide a platform for comparing the significance of sentiment across these markets, therefore, providing the evidence of the extent to which country/ region's investor sentiment matters the most.

Our choice of survey-based sentiment from Sentix stems from the fact that the alternate measure of survey-based sentiment is hard to obtain at the regional level. Furthermore, the survey-based sentiment proxy is measured for different countries/ regions, and cover a more heterogeneous and rich sets of questions than in other surveys-based proxies. For example, for the case of the US, he University of Michigan Consumer Confidence (UMCC) conducts monthly surveys of US households by posing just five questions of which only three are expectation-based. Furthermore, its survey sample size is very small, circa 500 households. Another survey-based proxy is conducted by the American Association of Institutional Investors (AAII), which conducts weekly surveys of individual investors and constructs sentiment index based on investors' response about their expectation of stock market in the next six months (i.e. bullish, bearish or neutral). The survey participants in the AAII has grown over 170,000 since 1987. ${ }^{1}$ In the case of Europe, the DirectorateGeneral for Economic and Financial Affairs (DG ECFIN) conducts both business and consumer surveys across all EEA countries, which consist of around 15 questions, with the sample size of circa 1,500 across all countries.

Given the inconsistencies in conducting the above mentioned investor's survey across different markets and countries, and in using different methodologies in deriving sentiment index, we opt for the survey-based sentiment index of Sentix. The advantage of using this Sentix index is that it asks the same question to all investors' across all the different countries/regions, and thus reflects more consistencies across these markets/regions. In fact, this sentiment index is constructed from the survey responses of around 1600 financial analysts and institutional investor, who express their opinion about the current and expected economic conditions over the next six months. Accordingly, the Sentix sentiment index reflects investors' expectations. The constructed index that

\footnotetext{
${ }^{1}$ The information on the AAII survey can be accessed at the following link: http://www.aaii.com/journal/article/analyzing-the-aaii-sentiment-survey-without-hindsight.
} 
we use for each country/ market takes into consideration sentiment of both individual and institutional investors and involves more than 36 different economic indicators. Furthermore, the data on this specific Sentix index is available at monthly frequencies for each country/ region. Several studies have used the Sentix index, but limit their analysis to specific asset classes (Schmeling, 2007; Heiden et al., 2010). For instance, Schmeling (2007) shows that the institutional and individual sentiment seems to act as a proxy for smart money and noise trader risk, respectively. Using private and institutional investors' sentiment data, Heiden et al. (2010) find that institutional sentiment significantly predicts returns over medium-term horizons in the EUR/USD market.

In determining the causality of sentiment across different economies, we, for the first time in the literature, use a novel approach of kernel-based multivariate causality, over and above standard linear Granger causality and entropy-based tests, to study sentiment spillovers in major global regions. This methodology controls for the possible existence of nonlinearity and regime changes (which we show to exists statistically), and hence, is a robust method compared to linear model-based tests. Our results, based on the robust nonlinear framework, show that causality runs from Eurozone to US, Asia, and Japan, with Japan also causing the Eurozone sentiment, and Latin-America causing Japanese sentiment. Interestingly, when we applied rolling estimations to detect time-varying causality for the cases of Eurozone and US, Eurozone and Asia, Eurozone and Japan, and LatinAmerica and Japan, we found evidence of bi-directional spillovers during certain months of the recent global financial crisis, and thereafter. Overall, our findings indicate that the sentiments of Japan, Asia, and the US are related quite strongly with that of the Eurozone, as is Japan and Latin America.

The rest of the paper is organized as follows: Section 2 provides a brief review of the literature, Section 3 presents the econometric approach, while Sections 4 discusses the data and empirical findings. Finally, Section 5 concludes.

\section{Literature Review}

The qualms about the soundness of market efficiency emerged subsequent the October 1987 stock market crash. The main reason for this market crash, according to Shiller (1987), was overpricing. The seminal study by Black (1986) showed that investors' trade on noise instead of fundamentals. De Long et al. (1990) formalized the role sentiment in financial markets where they show that sentiment changes lead to an increase in noise trading, mispricing and volatility when uninformed 
noise traders trade on sentiment and rational arbitrageurs experience limits to arbitrage. The authors further show that noise trading results in the pricing anomalies. Other studies have also found evidence of investors' underreacting and overreacting during the times of earnings announcement and good or bad news, which results in securities mispricing (Jegadeesh and Titman, 1993; Kothari and Shanken, 1997). Daniel et al. (1998) use psychological evidence to explore investors' behaviour and show that investors overreact to private information signals and underreact to public information signals.

Based on the evidence from the above studies, it can be said that investors depict irrational behaviour and make investment decisions based on noise instead of fundamentals. Such a behaviour can be quantified as an 'investor sentiment'. Baker and Wurgler (2007) define investor sentiment as a "belief about future cash flows and investment risks that are not justified by the facts at hand". The role of sentiment in affecting financial markets have been extensively examined in the finance literature over last two decades.

Previous studies have classified investor sentiment in two categories, viz. direct measure and indirect measure. The direct measure of sentiment includes 'survey-based' sentiment measure as they are directly obtained from surveying investors, whereas the indirect measure of sentiment includes 'market-based' sentiment proxies that are obtained from various financial market indicators (e.g. fund flow, derivative measures, closed-end fund discount, etc.) The monthly surveys are conducted across several developed and developing markets with the objective to determine investors' expectations about future economic conditions. The findings of survey sentiment in determining the predictive ability of stock returns is usually consistent across several markets. For instance, Fisher and Statman $(2000,2003)$ find that an rise in the US consumer confidence index is associated with an increase in bullishness of investor behaviour and subsequent lower returns. Using UMCC index and conference board index, Lemmon and Portniaguina (2006) find that consumer confidence index is useful in forecasting returns of small-cap stocks and stocks with low institutional ownership. Schmeling (2009) finds a negative relationship between consumer confidence index and future stock returns for 18 industrialized nations. Furthermore, the author shows that the impact of sentiment on stock returns is higher for countries which have less market integrity and are culturally more prone to herd-like behaviour and overreaction. Using survey data on investor sentiment, Brown and Cliff (2005) indicate that an increase in investor sentiment plays a significant role in affecting asset valuation. Bathia and Bredin. (2013) examine the significance of consumer confidence index on G7 
stock market returns, and find that value stocks relative to growth stocks are significantly affected by the survey sentiment. Despite different number and type of survey questions, different sample sizes and different methods in calculating the consumer confidence index, the findings of survey-based sentiment proxy are consistent across several developed and developing markets.

The indirect measure of sentiment, as known as market-based sentiment measure, reflects the collective behaviour of investors. Unlike survey-based sentiment measure, the findings for some of this market-based sentiment measure in affecting stock returns have been mixed. For instance, as Lee et al. (1991) consider that discount on closed-end funds (CEFD) are a proxy for the investor sentiment and find that when CEFD is high (low), investors are pessimistic (optimistic) about the future returns. However, these findings were subsequently challenged by several studies (Chen et al., 1993). Similarly, in the case of fund-flow, studies have linked the positive association between flow and stock returns to either price pressure effect or information effect (Warther, 1998; Brown et al. 2003; Bathia and Bredin, 2013). Several trading indicators, such as percentage change in short interest, change in margin debt, have been shown to reflect the levels of investor sentiment (Brown and Cliff, 2004). The information contained in a non-price derivative measure, like put-call ratio, has also been viewed as a measure of investor sentiment (Easley et al. 1998; Pan and Poteashman, 2006). Baker and Wurgler (2006) construct sentiment index for the US market from six raw sentiment proxies after removing business cycle variations form each of these raw proxies. This measure of sentiment is considered to represent a reliable measure of market sentiment. Due to the data availability issue for some of the above market-based sentiment measures for the countries/ regions that we study, we restrict our analysis to survey-based sentiment index of Sentix.

\section{Methodologies: Linear and Nonlinear Causality Tests}

Besides, the standard linear Granger causality test, in this segment we discuss another linear causality approach based on non-Gaussian assumptions, and also a nonlinear approach.

Hyärinen and Smith (2013) propose a new measure of the causal direction for more than two nonGaussian random variables, and even in the case of more variables than observations. Their method is based on the likelihood ratio under the linear non-Gaussian acyclic model (LiNGAM). Hyärinen and Smith (2013) extend the original method for estimating LiNGAM, which is based on first applying independent component analysis (ICA), to the data and then deduce the network connections from the results of ICA. In particular, Hyärinen and Smith (2013) propose an approach that uses the ratio of the likelihoods of the models corresponding to the two directions of causal 
influence, which they extend to first-order approximations and higher-order cumulants. They argue that their approach is more resistant to noise. Hyärinen and Smith (2013) show that a likelihood ratio is likely to provide a statistically powerful method because of the general optimality properties of likelihood. Their procedure of Granger-causality is elaborated as follows:

Assume that $\xi$ and $\eta$ are non-Gaussian standardized variables with mean zero mean and a unit variance. To measure the Granger causality from $\xi$ to $\eta$, we define our first model as $\eta=\rho \xi+$ $d$, where $\rho$ is the regression coefficient and $d$ is the error term that is independent of $\xi$. Conversely, to measure the Granger causality from $\eta$ to $\xi$, then the second model can be written as $\xi=\rho \eta+e$, where $e$ is the error term that is independent of $\eta$. Two important points emerge from the above two cases: (1) both models have $\rho$ which is equal to the correlation coefficient and (2) we do not assume $d$ or $e$ to be normal, have zero cumulants, or even to be non-Gaussian. In fact, we do not make any assumptions on the distributions of error terms and only assume that $\xi$ and $\eta$ are nonGaussian $^{2}$. The direction of Granger-causality between these two models (or variables) depends upon the value of their likelihoods and their ratios. The likelihood of the LiNGAM for the first case in which $\xi \rightarrow \eta$ may be, following Hyärinen et al. (2010), given by

$$
\log L(\xi \rightarrow \eta)=\left[\sum_{t} G_{\xi}\left(\xi_{t}\right)+G_{d}\left(\frac{\eta_{t}-\rho \xi_{t}}{\sqrt{1-\rho^{2}}}\right)\right]-T \log \left(1-\rho^{2}\right)
$$

where $G_{\xi}(u)=\log p_{\xi}(u)$, and $G_{d}$ is the standardised log-pdf of the residuals when regressing $\eta$ on $\xi$. The last term here is a normalization term due to the use of standardized log-pdf $G_{d}$. From this, we compute the likelihood ratio, which is normalized by $1 / \mathrm{T}$ for convenience:

$$
\begin{gathered}
R=\frac{1}{T} \log L(\xi \rightarrow \eta)-\frac{1}{T} \log L(\eta \rightarrow \xi)= \\
\frac{1}{T}\left[\sum_{t} G_{\xi}\left(\xi_{t}\right)+G_{d}\left(\frac{\eta_{t}-\rho \xi_{t}}{\sqrt{1-\rho^{2}}}\right)\right]-\left[\sum_{t} G_{\eta}\left(\eta_{t}\right)+G_{e}\left(\frac{\xi_{t}-\rho \eta_{t}}{\sqrt{1-\rho^{2}}}\right)\right]-T \log \left(1-\rho^{2}\right)
\end{gathered}
$$

From equation 2 we compute $\mathrm{R}$ and decide based on it what the causal direction is. If $\mathrm{R}$ is positive, we conclude $\xi \rightarrow \eta$, and if it is negative, we conclude $\eta \rightarrow \xi$. Hyärinen and Smith (2013) suggest that the statistically optimal way of estimating $\mathrm{R}$ would be to maximize the likelihood. Practically, that may be estimated by the conventional least-squares solution to the linear regression problem. As

2 This assumption is related to the identifiability theorem in ICA. It states that one of the latent variables can be nonGaussian (Comon, 1994). 
argued by Hyärinen and Smith (2013), that maximization of likelihood might be more robust against outliers, because log-likelihood functions often grow more slowly than the squaring function when moving away from the origin. Hyärinen and Smith (2013) further argue that the likelihood ratio has a simple information-theoretic interpretation, which implies that one may use well-known entropy approximations for its practical computation (even where we do not want to postulate functional forms for the G's). Taking the asymptotic limit of the likelihood ratio, we can obtain

$$
R \rightarrow-H(\xi)-H\left(\frac{\hat{d}}{\sigma_{d}}\right)+H(\eta)-H\left(\frac{\hat{e}}{\sigma_{e}}\right)
$$

where we denote differential entropy by $H$, the estimated residuals by $\hat{d}=\eta-\rho \xi, \hat{e}=\xi-\rho \eta$ and the variances of the estimated residuals by $\sigma_{d}^{2}, \sigma_{e}^{2}$. Another possible maximum entropy approximations is given by Hyärinen (1998) (for more details about the methodology refer to Hyärinen and Smith, 2013).

Next, given the possibility of a nonlinear relationship and structural breaks amongst the relationship between the sentiment indices, we now turn to Marinazzo et al. (2008), who introduced a novel approach to assess Granger causality that assumes nonlinearity and controls for overfitting to avoid the problem of false causalities.

Let $\left\{\xi_{n}\right\}_{n=1, \ldots, N+m}$ and $\left\{\eta_{n}\right\}_{n=1, \ldots, N+m}$ be two stationary time series, and consider autoregressive processes of order $m$ for these series as:

$$
\begin{gathered}
\xi_{n}=\sum_{j=1}^{m} A_{j} \xi_{n-j}+e_{n} \\
\xi_{n}=\sum_{j=1}^{m} A_{n}^{\prime} \xi_{n-j}+\sum_{j=1}^{m} B_{j} \eta_{n-j}+e_{n}^{\prime} .
\end{gathered}
$$

As Granger causality from $\eta$ to $\xi$ means that the variance of the residual $e_{n}^{\prime}$ is significantly lower than the variance of the residual $e_{n}$, the strength of Granger causality can be measured by an index as:

$$
\delta(\eta \rightarrow \xi)=1-\frac{\left\langle e_{n}^{\prime}\right\rangle}{\left\langle e_{n}\right\rangle}
$$

where $\langle\cdot\rangle$ represents the two means averaged over $n$ squared residuals. The index for reverse causality can be obtained by considering the processes in Eqs. (4)-(5) for the series $\eta$.

Let $X_{i}=\left(\xi_{i}, \ldots, \xi_{i+m-1}\right)^{T}$ and $Y_{i}=\left(\eta_{i}, \ldots, \eta_{i+m-1}\right)^{T}$, where $x_{i}=\xi_{i+m-1}$ and $y_{i}=\eta_{i+m-1}$ for $i=1, \ldots, N$; we treat these quantities as $N$ realizations of the stochastic variables $X, Y$, and of $x$ and 
$y$; respectively. Let us represent $\mathbf{X}$ as the $m \times N$ matrix having vectors $X_{i}$ as the columns, and $\mathbf{Z}$ as the $2 m \times N$ matrix having vectors $Z_{i}=\left(X_{i}^{T}, Y_{i}^{T}\right)^{T}$ as the columns. The values of $x$ are organized in the vector $x=\left(x_{1}, \ldots, x_{N}\right)^{T}$. In broadly general terms, we assume that each component of $X$ and $Y$ has a zero mean, and that vector $\mathbf{x}$ has a zero mean and is normalized, i.e., $\boldsymbol{X}^{T} \boldsymbol{X}=\mathbf{1}$. For each $i$ $=1, \ldots, N$, we define:

$$
\begin{gathered}
\tilde{x}_{i}=\sum_{j=1}^{m} A_{j} \xi_{i+m-j} \\
\tilde{x}_{i}^{\prime}=\sum_{j=1}^{m} A_{j}^{\prime} \xi_{i+m-j}+\sum_{j=1}^{m} B_{j} \eta_{i+m-j}
\end{gathered}
$$

where $\tilde{x}=\left(\tilde{x}_{1}, \ldots, \tilde{x}_{N}\right)^{T}$ and $\tilde{x}^{\prime}=\left(\tilde{x}_{1}^{\prime}, \ldots, \tilde{x}_{N}^{\prime}\right)^{T}$ are the values estimated by linear regression in both cases and have the following geometrical interpretation. Let $H \subseteq \Re^{N}$ be the range of the $N \times N$ matrix $\boldsymbol{K}=\mathbf{X}^{T} \boldsymbol{X} ; \tilde{\boldsymbol{x}}$ is the projection of $\mathbf{x}$ on $H$. So, calling $v_{1}, \ldots, v_{m}$ the (orthonormal) eigenvectors of $\mathbf{K}$ with non-vanishing eigenvalue and calling $P=\sum_{i=1}^{m} v_{i} v_{1}^{T}$ the projector in the space $H$, we have $\tilde{x}=P X$. Let $y=X-P X$ and $\widetilde{x^{\prime}}=P^{\prime} X, P^{\prime}$ be the projector in the $2 m$-dimensional space $H^{\prime} \subseteq \mathfrak{R}^{N}$, equal to the range of the matrix $\boldsymbol{K}^{\prime}=\mathbf{Z}^{T} \boldsymbol{Z}$. It is. Hence, easy to show that:

$$
\delta(\eta \rightarrow \xi)=\frac{\widetilde{\boldsymbol{X}}^{\prime T} \widetilde{\boldsymbol{X}}^{\prime}-\widetilde{\boldsymbol{X}}^{T} \widetilde{\boldsymbol{X}}}{1-\widetilde{\boldsymbol{X}}^{T} \widetilde{\boldsymbol{X}}}
$$

Given that $H^{\prime}$ can be decomposed as $H^{\prime}=H \oplus H^{\perp}$, where $H^{\perp}$ is the space of all vectors of $H^{\prime}$ orthogonal to all vectors of $H$, Eq. (9) can be re-written as:

$$
\delta(\eta \rightarrow \xi)=\frac{\left\|H^{\perp} y\right\|^{2}}{1-\widetilde{\boldsymbol{X}}^{T} \widetilde{\boldsymbol{X}}}
$$

Note that $H^{\perp}$ is the range of the matrix $\widetilde{\boldsymbol{K}}=\boldsymbol{K}^{\prime}-\boldsymbol{K}^{\prime} \boldsymbol{P}-\boldsymbol{P}\left(\boldsymbol{K}^{\prime}-\boldsymbol{K}^{\prime} \boldsymbol{P}\right)=\boldsymbol{K}^{\prime}-\boldsymbol{P} \boldsymbol{K}^{\prime}-\boldsymbol{K}^{\prime} \boldsymbol{P}+$ $\boldsymbol{P} \boldsymbol{K}^{\prime} \boldsymbol{P}$, so for any $\boldsymbol{u} \in \Re^{N}$, we have $\widetilde{\boldsymbol{K}} \boldsymbol{u}=\boldsymbol{v}-\boldsymbol{P} \boldsymbol{y}$, where $\boldsymbol{v}=\boldsymbol{K}^{\prime}(\boldsymbol{I}-\boldsymbol{P}) \boldsymbol{u} \in H^{\prime}$, and $\widetilde{\boldsymbol{K}} \boldsymbol{u} \in H^{\perp}$. It follows that $H^{\perp}$ is spanned by the set of the eigenvectors, $\boldsymbol{t}_{1}, \ldots, \boldsymbol{t}_{m}$, with non-vanishing eigenvalues, of $\widetilde{\boldsymbol{K}}$. We have that $\left\|H^{\perp} \boldsymbol{y}\right\|^{2}=\sum_{i=1}^{m} r_{i}^{2}$, where $\boldsymbol{r}_{i}$ is the Pearson's correlation coefficient of $\boldsymbol{y}$ and $\boldsymbol{t}_{i}$. Let $\boldsymbol{\pi}_{i}$ be the probability that $\boldsymbol{r}_{i}$ is due to chance, obtained by a Student's $t$ test. Since we are dealing with multiple comparisons, we use the Bonferroni correction to select the eigenvectors $\boldsymbol{t}_{i^{\prime}}$, correlated with $\mathbf{y}$, with an expected fraction of false positive $q$ (equal to 0.05). Therefore, we can obtain a filtered linear Granger causality index by summing only over the $\left\{\boldsymbol{r}_{i^{\prime}}\right\}$ such that $\boldsymbol{\pi}_{i^{\prime}}<\frac{q}{m}$ :

$$
\delta_{F}(\eta \rightarrow \xi)=\frac{\sum_{i^{\prime}} r_{i^{\prime}}^{2}}{1-\widetilde{X}^{T} \widetilde{X}}
$$


This index measures the causality from $\eta$ to $\xi$.

Using methods from the theory of RKHS (see Shawe-Taylor and Cristianini, 2004), the linear Granger causality can be generalized to the nonlinear case. Given a kernel function $K$, with the spectral representation $\boldsymbol{K}\left(\boldsymbol{X}, \boldsymbol{X}^{\prime}\right)=\sum_{\boldsymbol{a}} \boldsymbol{\lambda}_{\boldsymbol{a}} \boldsymbol{\phi}_{\boldsymbol{a}}(\boldsymbol{X}) \boldsymbol{\phi}_{\boldsymbol{a}}\left(\boldsymbol{X}^{\prime}\right)$ (see Mercer's theorem in Vapnik, 1998), we consider $H$, the range of the $N \times N$ Gram matrix $\mathbf{K}$ with the elements $\boldsymbol{K}\left(\boldsymbol{X}_{\boldsymbol{i}}, \boldsymbol{X}_{\boldsymbol{j}}\right)$. In order to make the mean of all variables $\boldsymbol{\phi}_{\boldsymbol{a}}(\boldsymbol{X})$ equal to zero, we replace $\mathbf{K} \rightarrow \mathbf{K}-P_{0} \mathbf{K}-\mathbf{K} P_{0}+P_{0} \mathbf{K} P_{0}$, where $P_{0}$ is the projector onto the one-dimensional subspace spanned by the vector such that each component is equal to unity (Shawe-Taylor and Cristianini, 2004). In what follows, we assume that this operation has been performed on each Gram matrix. As in the linear case, we calculate $\tilde{x}$, the projection of $\mathbf{x}$ onto $H$. Due to the fact that spectral representation of $\boldsymbol{K}, \tilde{x}$ coincides with the linear regression of $\mathbf{x}$ in the feature space spanned by $\sqrt{\lambda_{\boldsymbol{a}}} \boldsymbol{\phi}_{\boldsymbol{a}}$, the eigenfunctions of $K$, the regression is nonlinear in the original variables.

Using both $X$ and $Y$ to predict $x$, we evaluate the Gram matrix $\boldsymbol{K}^{\prime}$ with elements $K_{i j}^{\prime}=K\left(Z_{i}, Z_{j}\right)$. The regression values now form the vector $\tilde{x}^{\prime}$ as equal to the projection of $\mathbf{x}$ on $H^{\prime}$, the range of $\boldsymbol{K}^{\prime}$. Before we evaluate the filtered causality index, as in the linear case, we note that not all kernels may be used to evaluate Granger causality. Indeed, if $Y$ is statistically independent of $X$ and $x$, then $\tilde{x}^{\prime}$ and $\tilde{x}$ should coincide in the limit $N \rightarrow \infty$. This property - the invariance of the risk minimizer when statistically independent variables are added to the set of input variables - is satisfied only by suitable kernels, as discussed in Ancona and Stramaglia (2006). In what follows, we consider two possible choices that fulfil the invariance requirement.

We consider the inhomogeneous polynomial (IP) kernel of integer order $p$ is $\boldsymbol{K}_{\boldsymbol{p}}\left(\boldsymbol{X}, \boldsymbol{X}^{\prime}\right)=$ $\left(\mathbf{1}+\boldsymbol{X}^{\boldsymbol{T}} \boldsymbol{X}^{\prime}\right)^{\boldsymbol{p}}$, for which the eigenfunctions are made of all the monomials in the input variables up to the $p$ th degree. The dimension of the space $H$ is $m_{1}=\frac{1}{B(p+1, m+1)}-1$, where $B$ is the beta function and where $p=1$ corresponds to the linear regression. The dimension of space $\boldsymbol{H}^{\prime}$ is $m_{2}=$ $\frac{1}{B(p+1,2 m+1)}-1$. As in the linear case, we note that $H \subseteq H^{\prime}$ and decompose $H^{\prime}=H \oplus H^{\perp}$. Subsequently, we calculate $\widetilde{\boldsymbol{K}}=\boldsymbol{K}^{\prime}-\boldsymbol{P} \boldsymbol{K}^{\prime}-\boldsymbol{K}^{\prime} \boldsymbol{P}+\boldsymbol{P} \boldsymbol{K}^{\prime} \boldsymbol{P}$; the dimension of the range of $\widetilde{\boldsymbol{K}}$ is $m_{3}=m_{2}-m_{1}$. Along the same lines as those described in the linear case, we construct kernel- 
Granger causality taking into account only the eigenvectors of $\widetilde{\boldsymbol{K}}$ which pass the Bonferroni test, $\delta_{F}^{K}=\sum_{i^{\prime}} r_{i^{\prime}}^{2}$, with the sum only over the eigenvectors of $\widetilde{\boldsymbol{K}}$ with probability $\boldsymbol{\pi}_{i^{\prime}}<\frac{q}{m_{3}}$.

\section{Data and Results}

\subsection{Data}

We use the Sentix economic sentiment index, which is a survey-based sentiment indicator constructed and published by Sentix (www.sentix.de) on a monthly basis. The index is based on a monthly online survey among 1600 financial analysts and institutional investors who are asked to express their opinion about the current and expected economic conditions over the next six months. It consists of 36 different economic indicators and ranges between -100 (very bad, strongly deteriorating) and +100 (very good, strongly improving), with zero level indicating neutrality. An index value above (below) zero indicates that share of optimists are higher (lower) than the share of pessimists among participants. Our sample covers five countries/regions (United States (US), Latin America, Eurozone, Japan, Asia excluding Japan) for the period January 2003 to November 2017, as depicted by their availability from DataStream. The sample period consists of 179 monthly observations for each of the country/region. As shown in the Appendix Table A.1, the index of Asia excluding Japan has the highest mean, whereas that of the United States has the highest standard deviation. All sentiment indices are negatively skewed, and their kurtosis values are larger than the coefficient associated with normal distributions in 2 out of 5 cases. The data is plotted in Figure A1 in the Appendix. All indices seem to move in tandem, especially during the global financial crisis (GFC) where the US sentiment index, in particular, has reached the lowest levels. In early 2009, economic confidence in all the countries and regions under study rebounded sharply, and the level of most of the indices regained pre-GFC levels. However, the economic conditions in the Eurozone, in particular, have experienced a decline during 2012, which coincides with the Eurozone sovereign debt crisis. The sentiment index in Latin America has experienced a quite similar decline in late 2015 early 2016 as most of the economies in South America were hardly hit by commodity price collapse and an upsurge in the value of the US dollar.

\subsection{Empirical results}

To get a preliminary indication as to how these variables are related, we present in Figure 1 the scatter plots and the associated correlation. We observe from Figure 1 that correlation is quite high i.e., close to 0.7 or above 0.7 between Asia and Latin America, Japan and US, Asia and Japan, 
Eurozone and Japan. But correlation does not necessarily translate into causality, which is what we turn to next.

Figure 1: Pair-wise correlation and scatter plots of the series concerned

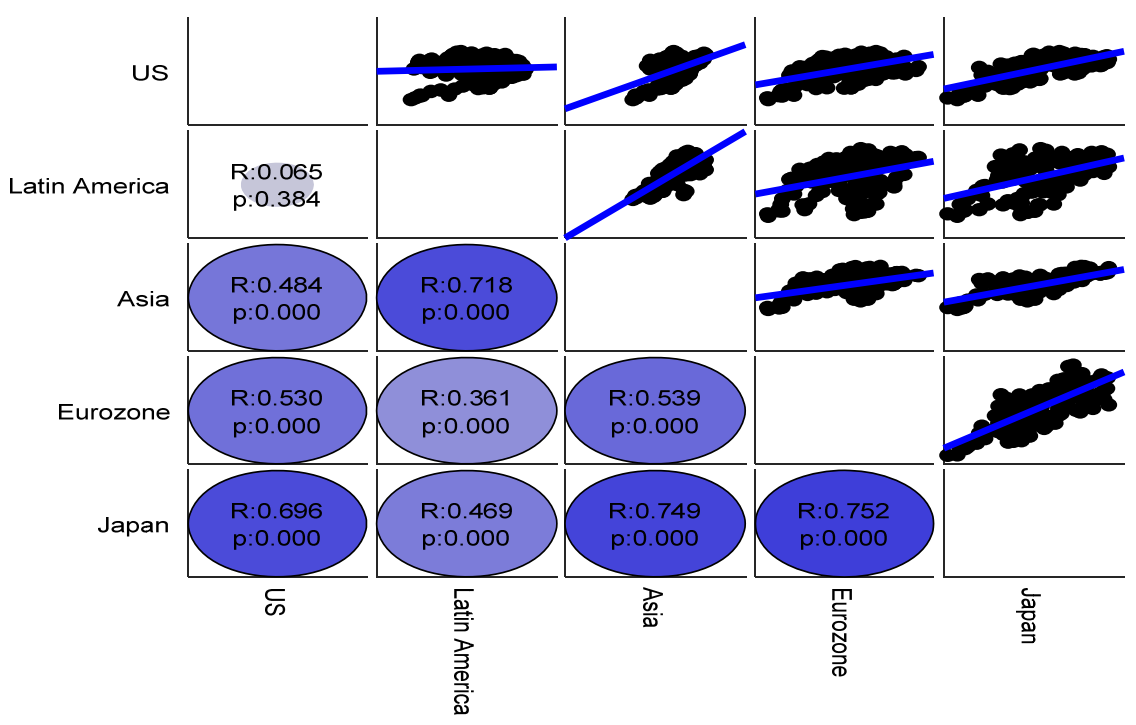

First, in Table 1, we present the results from Standard Granger causality tests between the sentiment indices in both bivariate and multivariate (i.e., where all the five indices are included) settings. The lag-length chosen was one, as suggested by both the Akaike Information and Schwarz Information Criteria. We observe a significant bivariate causality between the Eurozone and the US. Furthermore, Japan Granger causes the Eurozone. Sentiment in Japan is also found to be caused by the US and remaining of Asian sentiment indices. In the multivariate setting, Latin America, Eurozone and Japan sentiment indices are found to be caused by all the remaining sentiment indices. Overall, the most affected sentiments are that of the Eurozone, Japan, and Latin America.

Table 1. Linear Granger Causality Test

\begin{tabular}{|c|l|l|l|}
\hline Dependent variable & Independent variable & F-stat & P-value \\
\hline \multirow{3}{*}{ US SENTIX } & Latin America SENTIX & 0.96409 & 0.3275 \\
\cline { 2 - 4 } & Asia Excluding Japan & 0.09998 & 0.7522 \\
\cline { 2 - 4 } & Eurozone SENTIX & 4.89368 & $0.0282^{* *}$ \\
\hline
\end{tabular}




\begin{tabular}{|c|l|l|l|}
\hline \multirow{4}{*}{ Latin America SENTIX } & Japan SENTIX & 0.49888 & 0.4809 \\
\hline \multirow{5}{*}{ Asia Excluding Japan } & US SENTIX & 0.51481 & 0.4740 \\
\cline { 2 - 4 } & Asia Excluding Japan & 3.11539 & $0.0793^{*}$ \\
\cline { 2 - 4 } & Eurozone SENTIX & 0.35474 & 0.5522 \\
\cline { 2 - 4 } & Japan SENTIX & 0.36884 & 0.5444 \\
\hline & US SENTIX & $9.1 \mathrm{E}-06$ & 0.9976 \\
\cline { 2 - 4 } & Latin America SENTIX & 1.30186 & 0.2554 \\
\cline { 2 - 4 } & Eurozone SENTIX & 1.59651 & 0.2081 \\
\cline { 2 - 4 } & Japan SENTIX & 1.27460 & 0.2605 \\
\hline \multirow{3}{*}{ Eurozone SENTIX } & US SENTIX & 6.74050 & $0.0102^{* *}$ \\
\cline { 2 - 4 } & Latin America SENTIX & 0.52556 & 0.4694 \\
\cline { 2 - 4 } & Asia Excluding Japan & 1.64913 & 0.2008 \\
\cline { 2 - 4 } & Japan SENTIX & 5.69946 & $0.0180^{* *}$ \\
\hline \multirow{3}{*}{ Japan SENTIX } & US SENTIX & 4.87781 & $0.0285^{* *}$ \\
\cline { 2 - 4 } & Latin America SENTIX & 0.03483 & 0.8522 \\
\cline { 2 - 4 } & Asia Excluding Japan & 9.35149 & $0.0026^{* *}$ \\
\cline { 2 - 4 } & Eurozone SENTIX & 0.60787 & 0.4366 \\
\hline US SENTIX & All & 6.478066 & 0.1662 \\
\hline Latin America SENTIX & All & 10.65439 & $0.0307^{* *}$ \\
\hline Asia Excluding Japan & All & 3.461402 & 0.4838 \\
\hline Eurozone SENTIX & All & 9.835493 & $0.0433^{* *}$ \\
\hline Japan SENTIX & All & 17.75216 & $0.0014 * *$ \\
\hline
\end{tabular}

Note: ${ }^{* *}$ and $*$ indicates rejection of the null hypothesis of no Granger causality at 5 percent and 10 percent levels of significance, respectively.

Given that our variables are non-normal, we now turn our attention to the Granger-causality results based on linear non-Gaussian acyclic models. For this case, we present the causality results based on general Entropy method (while, for the sake of completeness, results from less-robust (Hyärinen and Smith (2013)) other methods have been presented in Figure A2 in the Appendix that tends to show varied strength of causality), using the Heatmap plot in Figure 2. Worthy to mention that in this figure, we plot the generated likelihood ratios (LR) matrix, and if entry $(\mathrm{i}, \mathrm{j})$ in that matrix is positive, it indicates that estimate of causal direction is $i \rightarrow j$ and, if it is negative it will imply that the causal direction is $j \rightarrow i$. In this figure colour range is from dark blue (zero strength of Grangercausality) to dark yellow (high strength of Granger-causality). Our observations from Figure 2 show that there is strong evidence of causality from US toJapan and Asia (excluding Japan), from LatinAmerica to Japan. These results are indeed, quite different from the linear Granger causality results presented in Table 1. 
Figure 2: General Entropy-based Granger-causality

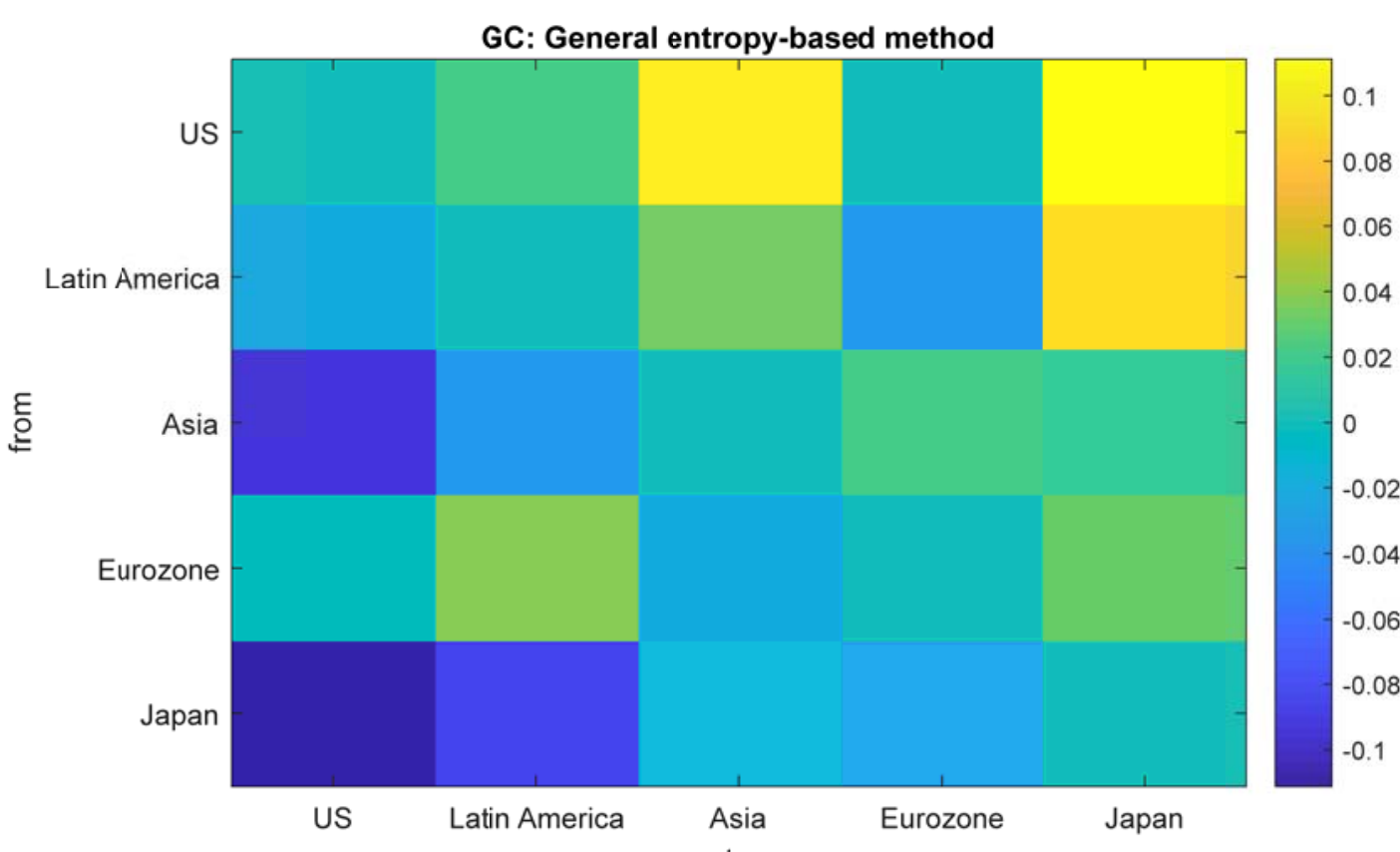

to

To motivate our nonlinear approach, we present in Tables 2 and 3, the Brock et al., (1996, BDS) test of nonlinearity (performed on the residuals of the equations involving the Granger causality tests), and Bai and Perron's (2003) multiple structural break results (performed on the equations used for the Granger causality tests) respectively, in both bivariate and multivariate settings. As can be seen, there is strong evidence of both nonlinearity and regime changes.

Table 2. Brock et al., (1996, BDS) Test of Nonlinearity

\begin{tabular}{|c|l|l|l|l|l|l|}
\hline Dependent variable & Independent variable & \multicolumn{5}{|c|}{ Dimension } \\
\cline { 3 - 7 } & & 2 & 3 & 4 & 5 & 6 \\
\hline \multirow{4}{*}{$\begin{array}{l}\text { US SENTIX } \\
\text { SENTIX }\end{array}$} & $4.257^{* * *}$ & $4.437^{* * *}$ & $-3.675^{* * *}$ & $-2.103^{* *}$ & -1.244 \\
\cline { 2 - 7 } & Asia Excluding Japan & $-2.777^{* *}$ & $-3.674^{* *}$ & $-4.377^{* * *}$ & $-2.502^{* *}$ & -1.496 \\
\cline { 2 - 7 } & EurOzone SENTIX & 0.893 & $-5.152^{* * *}$ & $-5.912^{* * *}$ & $-3.646^{* * *}$ & $-2.329^{* *}$ \\
\cline { 2 - 7 } & Japan SENTIX & $3.646^{* * *}$ & $1.816^{*}$ & $-4.624^{* * *}$ & $-2.691^{* *}$ & $-1.662^{*}$ \\
\hline \multirow{4}{*}{$\begin{array}{c}\text { Latin America } \\
\text { SENTIX }\end{array}$} & US SENTIX & $2.378^{* *}$ & $2.155^{* *}$ & $2.243^{* *}$ & $2.226^{* *}$ & $2.302^{* *}$ \\
\cline { 2 - 7 } & Asia Excluding Japan & $4.253^{* * *}$ & 0.778 & $-4.755^{* * *}$ & $-2.784^{* *}$ & $-1.79^{*}$ \\
\cline { 2 - 7 } & Eurozone SENTIX & $2.190^{* *}$ & $1.976^{* *}$ & $2.098^{* *}$ & $2.127^{* *}$ & $2.201^{* *}$ \\
\cline { 2 - 7 } & Japan SENTIX & $2.141^{* *}$ & $1.924^{* *}$ & $2.095^{* *}$ & $2.123^{* *}$ & $2.189^{* *}$ \\
\hline \multirow{2}{*}{$\begin{array}{c}\text { Asia Excluding } \\
\text { Japan }\end{array}$} & US SENTIX & $-3.936^{* * *}$ & $-2.633^{* *}$ & $-4.973^{* * *}$ & $-2.914^{* *}$ & $-1.838^{*}$ \\
\cline { 2 - 7 } & $\begin{array}{l}\text { Latin America } \\
\text { SENTIX }\end{array}$ & $-2.639^{* *}$ & -0.775 & $3.134^{* *}$ & $-2.792^{* *}$ & $-1.751^{*}$ \\
\hline
\end{tabular}




\begin{tabular}{|c|l|l|l|l|l|l|}
\hline \multirow{5}{*}{ Eurozone SENTIX } & Eurozone SENTIX & $-3.429^{* * *}$ & $-7.849^{* * *}$ & $-4.048^{* * *}$ & $-2.298^{* *}$ & -1.421 \\
\cline { 2 - 7 } & Japan SENTIX & $-4.112^{* * *}$ & $-7.559^{* * *}$ & $-3.895^{* * *}$ & $-2.187^{* *}$ & -1.315 \\
\hline & US SENTIX & $2.184^{* *}$ & $3.489^{* * *}$ & $-4.644^{* * *}$ & $-2.737^{* *}$ & $-1.666^{*}$ \\
\cline { 2 - 7 } & Latin America & -0.982 & $4.241^{* * *}$ & $23.473^{* * *}$ & $-1.973^{* *}$ & -1.223 \\
\cline { 2 - 7 } & Asia Excluding Japan & $-2.327^{* *}$ & $-2.163^{* *}$ & $-2.832^{* *}$ & -1.553 & -0.871 \\
\cline { 2 - 7 } & Japan SENTIX & 1.522 & $6.444^{* * *}$ & $29.773^{* * *}$ & $-1.716^{*}$ & -1.005 \\
\hline \multirow{4}{*}{ Japan SENTIX } & US SENTIX & $2.033^{* *}$ & $1.786^{*}$ & $1.890^{*}$ & $2.697^{* *}$ & $3.307^{* * *}$ \\
\cline { 2 - 7 } & $\begin{array}{l}\text { Latin America } \\
\text { SENTIX }\end{array}$ & $2.420^{* *}$ & $2.218^{* *}$ & $2.127^{* *}$ & $2.843^{* *}$ & $3.484^{* * *}$ \\
\cline { 2 - 7 } & Asia Excluding Japan & $2.111^{* *}$ & $10.635^{* * *}$ & $13.921^{* * *}$ & $-4.019^{* * *}$ & $-2.585^{* *}$ \\
\cline { 2 - 6 } & Eurozone SENTIX & $2.524^{* *}$ & $2.276^{* *}$ & $2.210^{* *}$ & $2.961^{* *}$ & $3.643^{* * *}$ \\
\hline US SENTIX & All & $3.146^{* * *}$ & $-4.311^{* * *}$ & $-5.196^{* * *}$ & $-3.128^{* * *}$ & $-1.972^{*}$ \\
\hline $\begin{array}{c}\text { Latin America } \\
\text { SENTIX }\end{array}$ & All & 1.572 & $5.092^{* * *}$ & $4.437^{* * *}$ & $-4.360^{* * *}$ & $-2.880^{* *}$ \\
\hline $\begin{array}{c}\text { Asia Excluding } \\
\text { Japan }\end{array}$ & All & $-1.820^{*}$ & $3.970^{* * *}$ & $-5.171^{* * *}$ & $-3.076^{* *}$ & $-1.995^{* *}$ \\
\hline Eurozone SENTIX & All & $5.864^{* * *}$ & $4.338^{* * *}$ & $-3.853^{* * *}$ & $-2.215^{* *}$ & -1.363 \\
\hline Japan SENTIX & All & $-3.282^{* * *}$ & $-4.167^{* * *}$ & $-7.663^{* * *}$ & $-4.745^{* * *}$ & $-3.109^{* * *}$ \\
\hline
\end{tabular}

Note: Entries correspond to the z-statistic of the BDS test with the null of i.i.d. residuals, with the test applied to the residuals recovered from the bivariate or multivariate (ALL) causality equations; $* * *, * *$, and $*$ indicates rejection of the null hypothesis at 1 percent, 5 percent and 10 percent levels of significance, respectively.

Table 3. Bai-Perron (2003) Multiple Structural Break Test

\begin{tabular}{|l|l|l|}
\hline Dependent variable & Independent variable & Date \\
\hline \multirow{5}{*}{ US SENTIX } & Latin America SENTIX & $\begin{array}{l}\text { 2006M06, 2008M12, } \\
\text { 2013M05 }\end{array}$ \\
\cline { 2 - 3 } & Asia Excluding Japan & $\begin{array}{l}\text { 2006M06, 2008M12, } \\
\text { 2012M01, 2014M03 }\end{array}$ \\
\cline { 2 - 3 } & Eurozone SENTIX & $\begin{array}{l}2006 \mathrm{M} 06,2009 \mathrm{M} 04, \\
2011 \mathrm{M} 12,2014 \mathrm{M} 09\end{array}$ \\
\cline { 2 - 3 } & Japan SENTIX & $2005 \mathrm{M} 10,2009 \mathrm{M} 04$, \\
& & $2012 \mathrm{M} 01,2014 \mathrm{M} 03$ \\
\hline \multirow{5}{*}{ Latin America SENTIX } & US SENTIX & $2005 \mathrm{M} 04,2008 \mathrm{M} 10$, \\
& & $2011 \mathrm{M} 03,2013 \mathrm{M} 07$ \\
\cline { 2 - 3 } & Asia Excluding Japan & $2005 \mathrm{M} 04,2008 \mathrm{M} 04$, \\
& & $2012 \mathrm{M} 06,2014 \mathrm{M} 08$ \\
\cline { 2 - 3 } & Eurozone SENTIX & $2009 \mathrm{M} 08,2013 \mathrm{M} 07$ \\
\cline { 2 - 3 } & Japan SENTIX & $2006 \mathrm{M} 12,2009 \mathrm{M} 08$, \\
& & $2013 \mathrm{M} 07$ \\
\hline \multirow{5}{*}{ Asia Excluding Japan } & US SENTIX & $2008 \mathrm{M} 07,2011 \mathrm{M} 02$, \\
& & $2013 \mathrm{M} 07$ \\
\cline { 2 - 3 } & Latin America SENTIX & $2005 \mathrm{M} 04,2007 \mathrm{M} 11$, \\
& & $2013 \mathrm{M} 10$ \\
\cline { 2 - 3 } & Eurozone SENTIX & $2005 \mathrm{M} 04,2007 \mathrm{M} 10$, \\
\hline
\end{tabular}




\begin{tabular}{|c|c|c|}
\hline & & 2009M10, 2015M06 \\
\hline & Japan SENTIX & $\begin{array}{l}\text { 2005M04, 2009M08, } \\
\text { 2013M05 }\end{array}$ \\
\hline \multirow{4}{*}{ Eurozone SENTIX } & US SENTIX & $\begin{array}{l}\text { 2005M10, 2008M07, } \\
\text { 2011M12, 2015M03 }\end{array}$ \\
\hline & Latin America SENTIX & $\begin{array}{l}\text { 2006M01, 2008M06, } \\
\text { 2011M07, 2013M09 }\end{array}$ \\
\hline & Asia Excluding Japan & $\begin{array}{l}\text { 2005M08, 2007M11, } \\
\text { 2011M07, 2013M09 }\end{array}$ \\
\hline & Japan SENTIX & $\begin{array}{l}\text { 2006M11, 2011M08, } \\
\text { 2015M01 }\end{array}$ \\
\hline \multirow{4}{*}{ Japan SENTIX } & US SENTIX & 2005M06, 2008M10 \\
\hline & Latin America SENTIX & $\begin{array}{l}\text { 2007M08, 2010M04, } \\
\text { 2013M05 }\end{array}$ \\
\hline & Asia Excluding Japan & $\begin{array}{l}\text { 2005M06, 2007M08, } \\
\text { 2013M05 }\end{array}$ \\
\hline & Eurozone SENTIX & $\begin{array}{l}\text { 2006M11, 2009M08, } \\
\text { 2013M01, 2015M04 }\end{array}$ \\
\hline US SENTIX & All & $\begin{array}{l}\text { 2007M09, 2009M11, } \\
\text { 2013M07 }\end{array}$ \\
\hline Latin America SENTIX & All & $\begin{array}{l}\text { 2005M04, 2008M10, } \\
\text { 2011M05, 2014M08 }\end{array}$ \\
\hline Asia Excluding Japan & All & $\begin{array}{l}\text { 2008M07, 2011M05, } \\
\text { 2014M11 }\end{array}$ \\
\hline Eurozone SENTIX & All & $\begin{array}{l}\text { 2006M01, 2009M01, } \\
\text { 2011M12, 2015M02 }\end{array}$ \\
\hline Japan SENTIX & All & $\begin{array}{l}\text { 2005M06, 2007M09, } \\
\text { 2013M05 }\end{array}$ \\
\hline
\end{tabular}

Note: Entries correspond to the monthly break dates detected by applying the Bai and Perron (2003) test of structural breaks on the bivariate or multivariate (ALL) causality equations.

Given this, we present the kernel based non-linear Granger-causality in a multivariate setting using Heat-map plots in Figure 3. Again as above, in this figure colour range is from dark blue (zero strength of Granger-causality) to dark yellow (high strength of Granger-causality). We observe from Figure 3, that strong evidence of Granger-causality is observed Eurozone to US, Asia, and Japan, with Japan also causing the Eurozone sentiment. Also, Latin-America is found to cause Japanese sentiment. Though some of the conclusions of the linear models-based tests do carry over here, given the existence of nonlinearity and regime changes, we deem these results to be more robust than those reported in Table 1 and Figure 2 based on linear models. 


\section{Figure 3: Kernel based non-linear Granger-causality in multivariate setting}

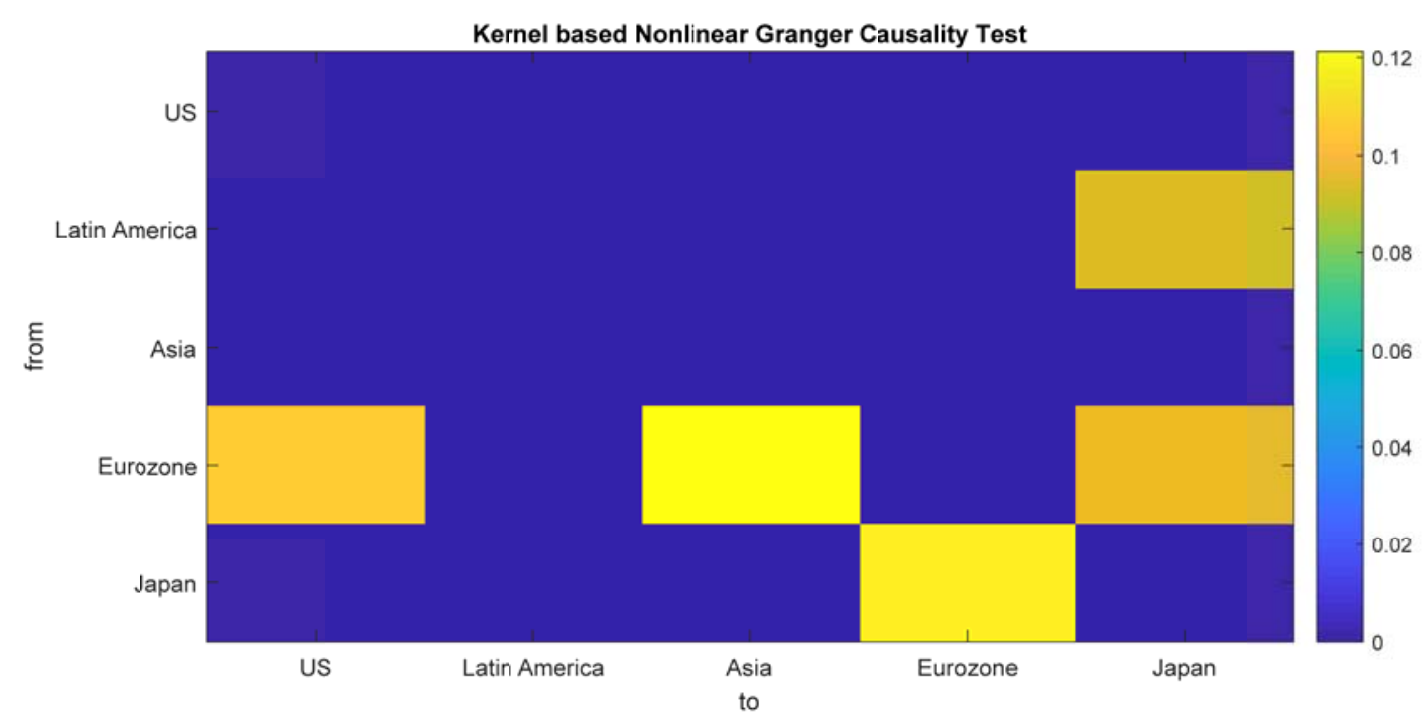

Given the existence of structural breaks, in Figures 4 to 7, we present the time-varying (rolling window of 60 observations) results for the Granger causality of sentiment index of US, Latin America, Eurozone, Japan and Asia (excluding Japan), along with the rolling correlation coefficients between their pairs, based on our kernel-based nonlinear Granger causality test. Note the window size of 5 years, allows us to conduct the analysis from January 2008, i.e., we can analyze timevariation in the causal relationship of the sentiments during and post the recent global financial crisis. We consider four pairs, namely: Eurozone and US, Eurozone and Japan, Eurozone and Asia (excluding Japan), Latin-America and Japan. For each pair, we present a figure to show the Grangercausality in both directions and correlations hence, results for each pair is presented in three part of a single figure wherein first two parts of the figure are related to presenting the results of Grangercausality; the third part of the figure presents correlation results. It is important to remember that the vertical axis in the first two plots in each figure represents the strength of causality and the last plot presents the correlation value between each pair. The non-Granger causality is indicated by the $\delta_{F}$ values being zero will indicate the zero strength of the Granger causality (or no Grangercausality). Contrarily, for values higher than the zero horizontal line, the evidence supports Grangercausality, and the higher the value, the higher the strength of a Granger-causality.

In Figure 4, the results of rolling causality between Eurozone and US indicate evidence of bidirectional predictability in December of 2006, and evidence of unidirectional causality from Eurozone to the US in August of 2009 and 2013, and March of 2015, and also unidirectional 
causality from the US to Eurozone in December of 2010. The overall rolling correlation results show that the relationship between the two sentiment indices is positive for the entire period except for December of 2006 and January of 2007, and October- November of 2017. Next, we turn to the results of rolling causality between Eurozone and Japan; as shown in Figure 5, Japan Granger causes Eurozone during April-May of 2015, and October of 2017, whereas Eurozone Granger-causes Japan in June of 2009, November of 2013, and July to December of 2015. The overall correlation is positive during the entire study period. However, it became close to zero in January of 2008, August of 2013, and December of 2016-January of 2017.

Figure 4. Results for rolling Granger causality between Eurozone and the US
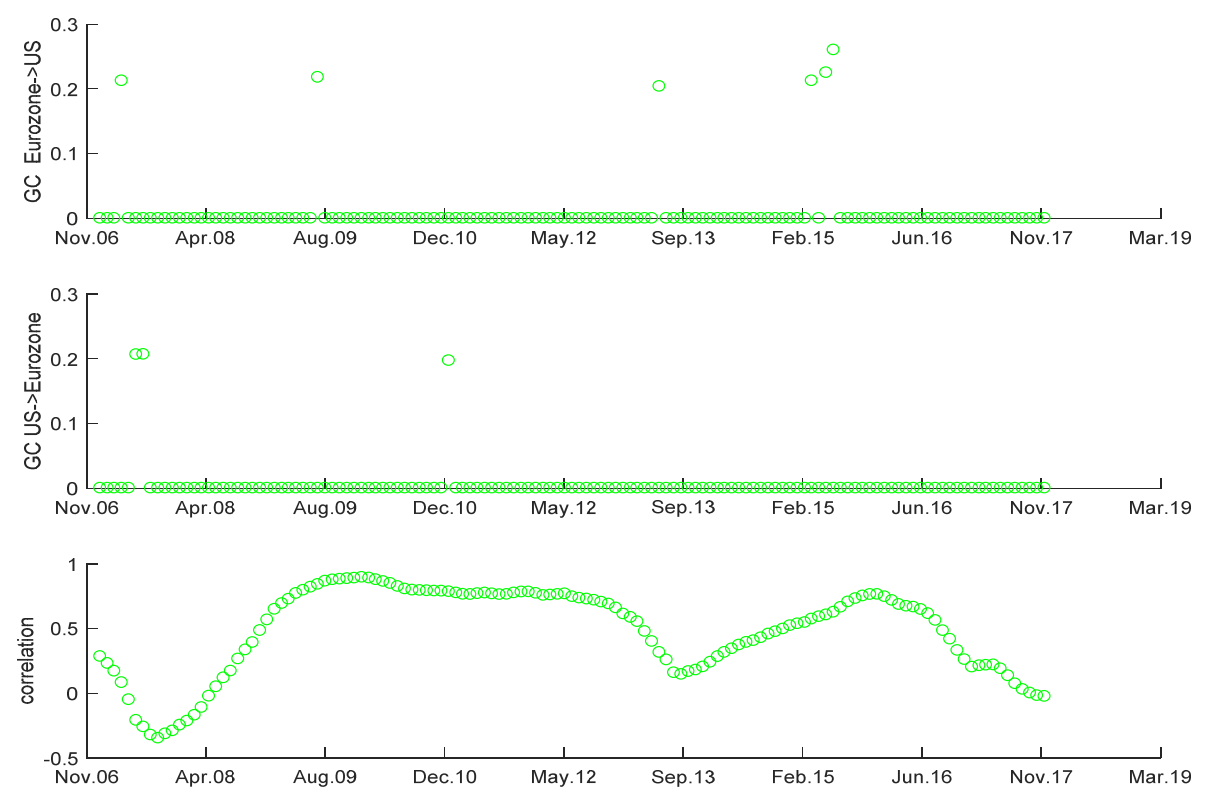
Figure 5. Results for rolling Granger causality between Eurozone and Japan
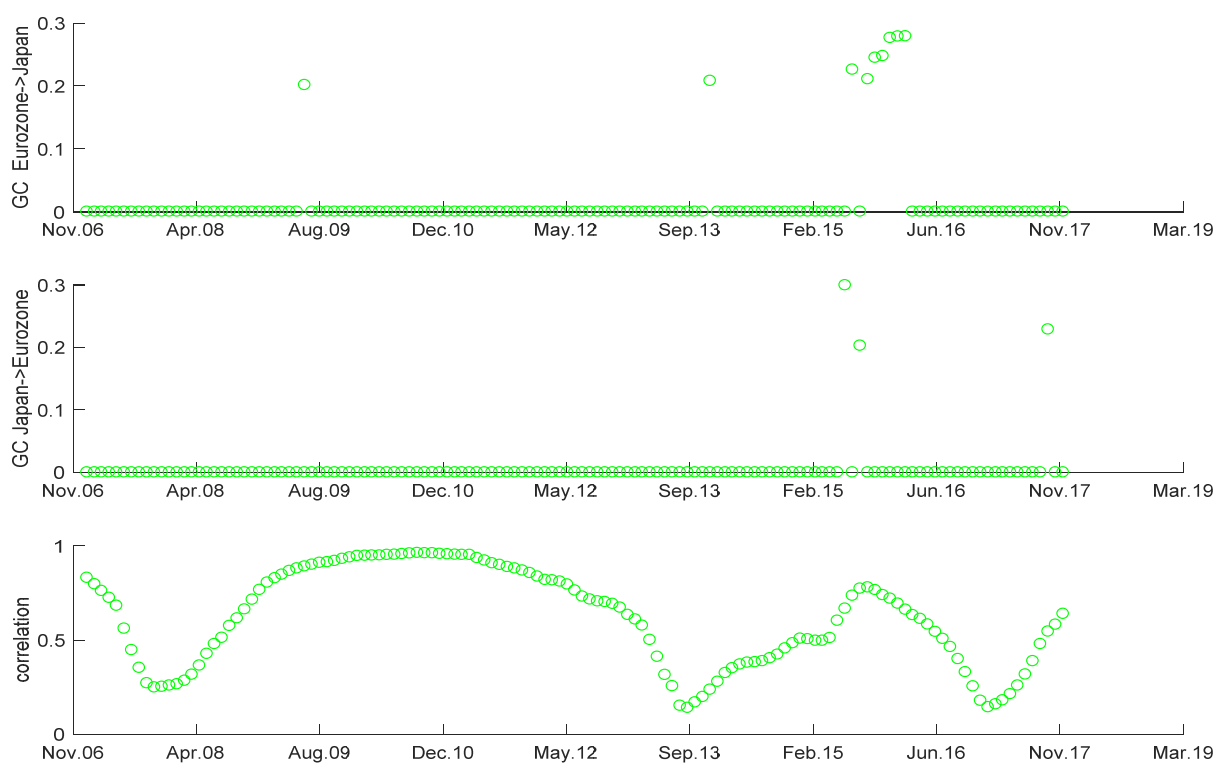

Figure 6. Results for rolling Granger causality between Eurozone and Asia (excluding Japan)
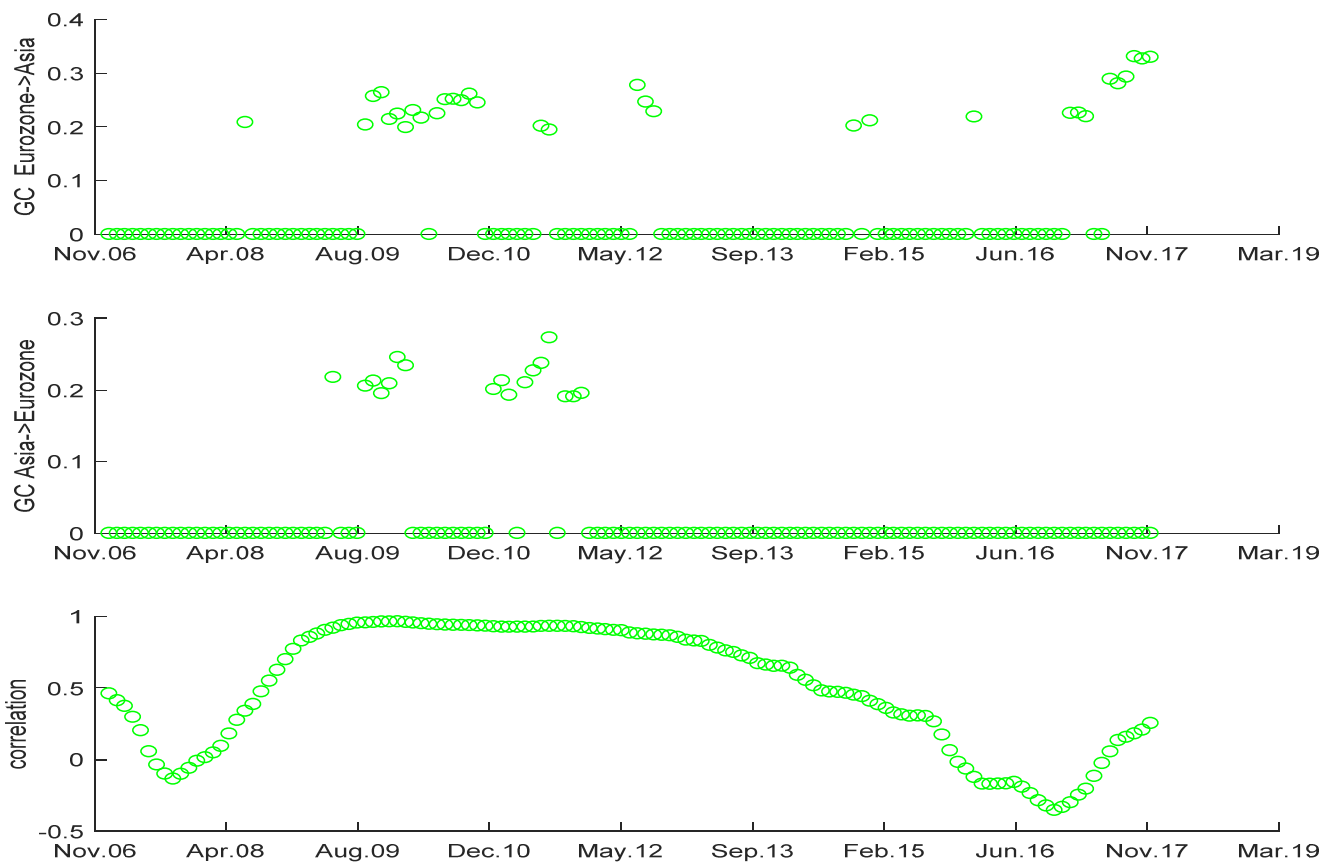
Figure 7. Results for rolling Granger causality between Japan and Latin-America.

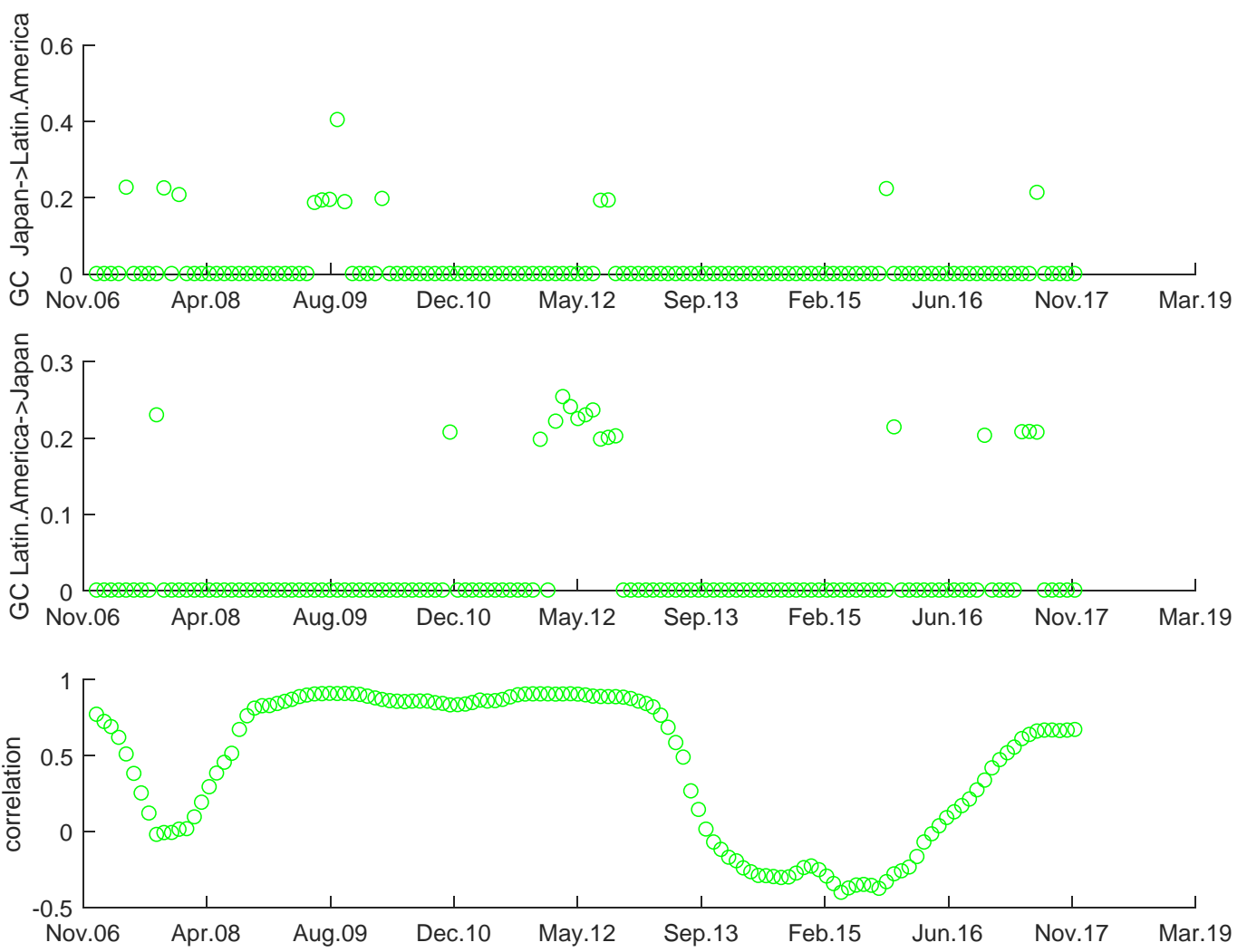

Now, the results of causality between Eurozone and Asia (excluding Japan), as plotted in Figure 6, indicate that causality is stronger from Eurozone to Asia than vice versa. Specifically, Eurozone Granger causes Asia in May of 2008, August of 2009 to December of 2010, May of 2011, July of 2012, December of 2014, January of 2016 and 2017; whereas Asia (excluding Japan) Granger causes Eurozone in June of 2009, September to November of 2009, and the entire year of 2011. The overall correlation results are in general positive except from early 2016, with it tending to become positive towards the end of the sample. Some negative correlation is also observed in the mid-2007. Finally, in Figure 7, we present the results of causality between Japan and Latin-America, which indicate Japan Granger causes Latin-America in December of 2006, February of 2008, July to September of 2009, July of 2012, January of 2016 and September of 2017; whereas Latin-America Granger-causes Japan in January of 2008, the entire year of 2012, January and December of 2016 and August of 2016. The overall correlations are positive till mid of 2013 (with the exception of 
early 2008), and during September of 2013-to June of 2016, the correlation is negative, which again becomes positive in 2017 .

\section{Conclusions}

This paper aims to analyze sentiment spillovers across US, Latin America, Eurozone, Japan and Asia (excluding Japan), based on monthly data covering the period from January 2003 to November 2017. Using a survey-based sentiment index of 'Sentix', we postulate this problem in the context of a rich causality testing framework. Though we start with standard linear and an entropy-based causality tests, statistical evidence show the existence of nonlinearity and structural breaks making the results from linear causality models unreliable. Hence, using a kernel-based multivariate nonlinear causality test, we find that causality runs from Eurozone to US, Asia, and Japan, with Japan also causing the Eurozone sentiment, and Latin-America causing Japanese sentiment. Interestingly, when we applied rolling estimations to detect time-varying causality for the cases of Eurozone and US, Eurozone and Asia, Eurozone and Japan, and Latin-America and Japan, we found evidence of bi-directional spillovers during certain months of the recent global financial crisis, and thereafter. Overall, our findings indicate that the sentiments of Japan, Asia, and the US are related quite strongly with that of the Eurozone, as is Japan and Latin America.

The importance of movements in sentiment on the macroeconomy and financial markets is quite well-recognized, hence, if along with a domestic shock to sentiment, there is also a foreign shock at the same time, especially one that originates from the Eurozone, the effect of the domestic sentiment shock in US, Japan and Asia are likely to be prolonged. Similar implications can also be drawn for Japan following a shock to Latin-American sentiment and that of the Eurozone due to a change in Japanese sentiment.

\section{References}

Ancona, N., Stramaglia, S., 2006. An Invariance Property of Predictors in Kernel-Induced Hypothesis Spaces. Neural Computation 18 (4): 749-759.

Bai, J. and Perron, P., 2003. Computation and analysis of multiple structural change models. Journal of Applied Econometrics, 18(1): 1-22.

Ball R. 2009. The global financial crisis and the efficient market hypothesis: what have we learned? Journal of Applied Corporate Finance 21: 8-16. 
Baker M, Wurgler J. 2006. Investor sentiment and the cross-section of stock returns. Journal of Finance 61: 1645-1680.

Baker M, Wurgler J. 2007. Investor sentiment in the stock market. Journal of Economic Perspectives 21: 129-151.

Baker M, Wurgler J, Yuan Y. 2012. Global, local and contagious investor sentiment. Journal of Financial Economics 104: 272-87.

Bathia D, Bredin D. 2013. An examination of investor sentiment effect on G7 stock market returns. European Journal of Finance 19: 909-937.

Bathia, D., Bredin, D., and Nitzsche, D., 2016. International sentiment spillovers in equity returns. International Journal of Finance and Economics 21: 332-359.

Brock, W., Dechert, D., Scheinkman, J., LeBaron, B., 1996. A test for independence based on the correlation dimension. Econometric Reviews, 15, 197-235.

Brown, S., Goetzmann, W., Hiraki, T., Shiraishi, N., and Watanabe, N., 2003. Investor Sentiment in Japanese and US Daily Mutual Fund Flows.Working Paper. NBER 9470.

Brown G, Cliff M. 2004. Investor sentiment and the near term stock market. Journal of Empirical Finance 11: 1-27.

Brown G, Cliff M. 2005. Investor sentiment and asset valuation. Journal of Business 78: 405-440.

Chen, N., Kan, R., and Miller, M., 1993. Are the discounts on closed-end funds a sentiment index? Journal of Finance 58: 795-800.

Daniel, K., D. Hirshleifer, and A. Subrahmanyam. 1998. Investor psychology and security market under and overreactions. Journal of Finance 53(6): 1839-85.

De Long J., Shleifer, A., Summers, L., Waldmann, R. 1990. Noise trader risk in financial markets. Journal of Political Economy 98. 703 - 738.

Easley, D., O'Hara, M., and Srinivas, P., 1998. Option volume and stock prices: Evidence on where informed traders trade. Journal of Finance 53: 431-465.

Fisher, K., and M. Statman. 2000. Investor sentiment and stock returns. Financial Analysts Journal 56(2): 2: 16-23. 
Fisher, K., and M. Statman. 2003. Consumer confidence and stock returns. Journal of Portfolio Management 30, no. 1:115-27.

Heiden, S., Klein, C., and Zwergel, B., 2011. Beyond Fundamentals: Investor Sentiment and Exchange Rate Forecasting. European Financial Management 19(3): 558-578.

Jegadeesh, N., and S. Titman. 1993. Returns to buying winners and selling losers: Implications for stock market efficiency. Journal of Finance 48(1): 65-91.

Kothari, S., and J. Shanken. 1997. Book-to-market, dividend yield and expected market returns: A time series analysis. Journal of Financial Economics 44(2): 169-203.

Lee, C., Shleifer, A., and Thaler, R., 1991. Investor Sentiment and the Closed-End Puzzle. Journal of Finance 46: 75-109.

Lemmon M, Portniaguina E. 2006. Consumer confidence and asset prices: some empirical evidence. Review of Financial Studies 19: 1499-1529.

Marinazzo, D., Pellicoro, M., Stramaglia, S., 2008. Kernel methods of nonlinear causality. Physical Review Letters 100: 144103-1-144103-4.

Pan, J., and Poteshman, A., 2006. The Information in Option Volume for Future Stock Prices. Review of Financial Studies 19: 871-908.

Schmeling, M. (2007). Institutional and individual sentiment: Smart money and noise trader risk? International Journal of Forecasting, 23(1): 127-145.

Schmeling, M., 2009. Investor sentiment and stock returns: Some international evidence. Journal of Empirical Finance 16: 394-408.

Shawe-Taylor, J., Cristianini, N., 2004. Kernel Methods for Pattern Analysis. Cambridge University Press, London, 2004.

Shiller, R.J., 1987. Investor Behaviour in the October 1987 Stock Market Crash: Survey Evidence. NBER Working Paper

Shiller, R.J., 1995. Conversation, Information, and Herd Behavior, American Economic Review 85(2): 181-185.

Thaler, R.H., 2000. From Homo Economicus to Homo Sapiens, Journal of Economic Perspectives 14(1): 133-141. 
Vapnik, V., 1998. Statistical Learning Theory. Wiley, New York, 1998.

Verma R, Soydemir G. 2006. The impact of US individual and institutional investor sentiment on foreign stock market. Journal of Behavioural Finance 7: 128-144.

Warther, V., 1995. Aggregate mutual fund flows and security returns. Journal of Fiinancial Economics 39: 209-235.

\section{APPENDIX:}

Figure A1. Data Plots

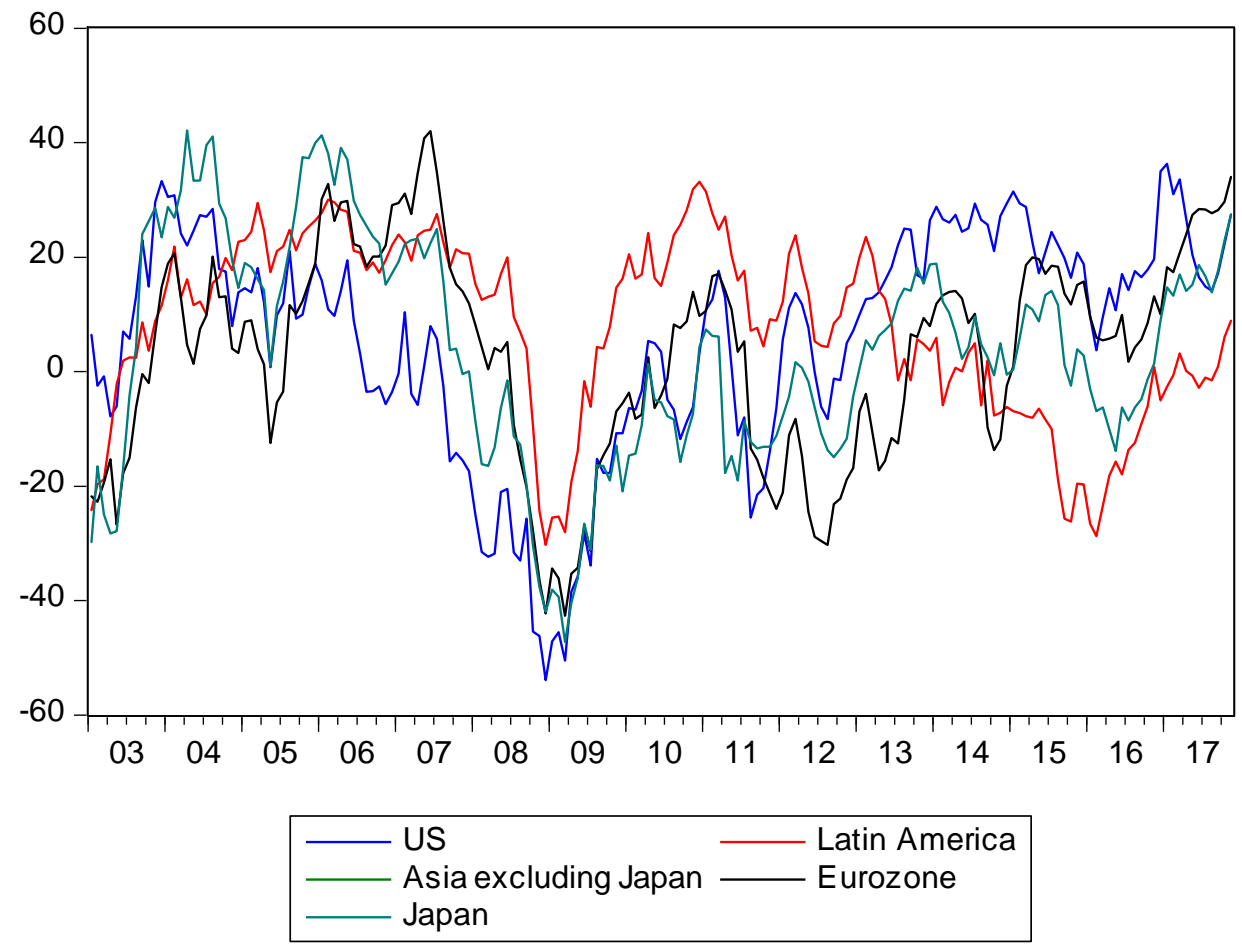

Table A1. Summary Statistics

\begin{tabular}{lrcrrr}
\hline \multicolumn{1}{c}{ US } & LATIN AMERICA & JAPAN & EUROZONE & \multicolumn{1}{c}{ JAPAN } \\
\hline Mean & 5.658174 & 7.562668 & 24.79495 & 3.249330 & 3.825950 \\
Maximum & 36.28850 & 33.14910 & 57.12560 & 42.02000 & 42.11770 \\
Minimum & -53.90590 & -30.29710 & -23.63890 & -42.67000 & -47.25940 \\
Std. Dev. & 19.72223 & 15.54719 & 15.84511 & 18.32269 & 19.28108
\end{tabular}




\begin{tabular}{lccccc} 
Skewness & -0.931126 & -0.601901 & -0.504043 & -0.380655 & -0.189233 \\
Kurtosis & 3.361109 & 2.503859 & 3.545573 & 2.521095 & 2.627601 \\
Jarque-Bera & 26.83794 & 12.64407 & 9.799421 & 6.033362 & 2.102637 \\
Probability & 0.000001 & 0.001796 & 0.007449 & 0.048963 & 0.349477 \\
Observations & 179 & 179 & 179 & 179 & 179 \\
\hline
\end{tabular}

Note: This table presents summary statistics of monthly levels of the Sentix economic sentiment index for the US, Latin

America, Eurozone, Japan, and Asia excluding Japan. The sample period is from January 2003 to November 2017.

Figure A2. Additional Results from Linear Non-Gaussian Acyclic Models
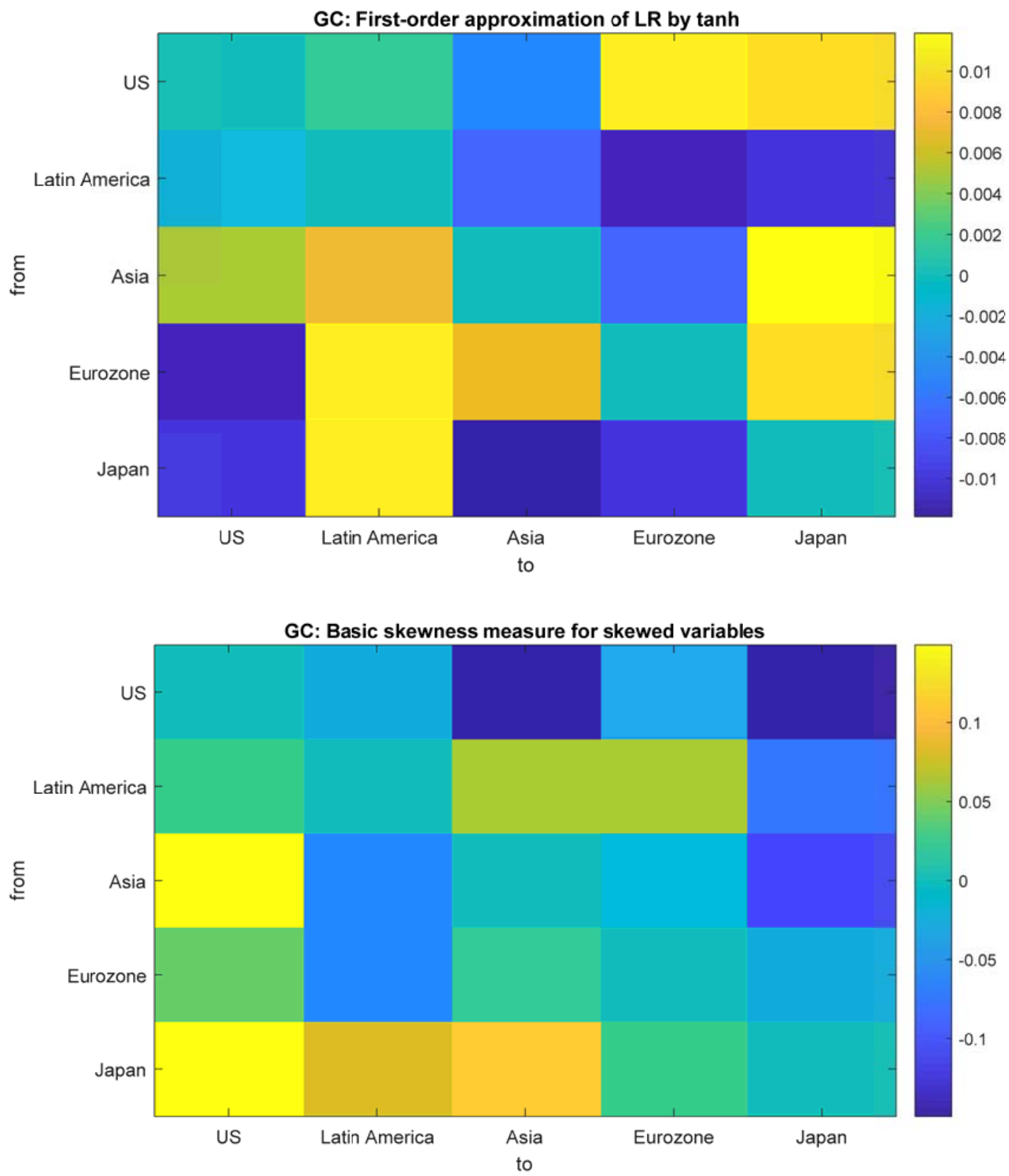

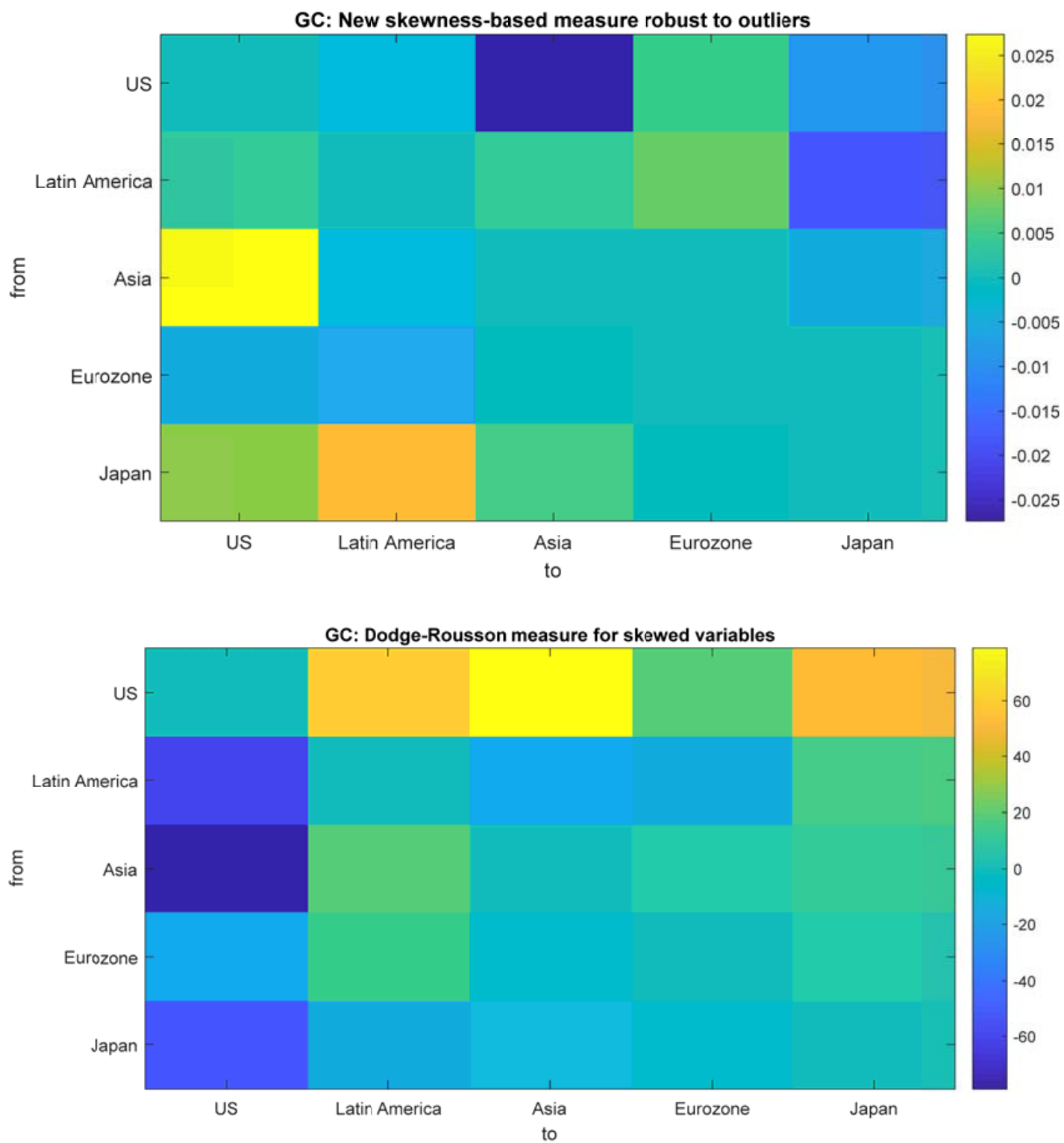